\title{
Using of simulation for comparison of technologies for pallets storing
}

Pavel Kř́̌ž, Bronislav Chramcov, and Milan Jemelka

Citation: AIP Conference Proceedings 1738, 120027 (2016); doi: 10.1063/1.4951910

View online: http://dx.doi.org/10.1063/1.4951910

View Table of Contents: http://aip.scitation.org/toc/apc/1738/1

Published by the American Institute of Physics 


\title{
Using of Simulation for Comparison of Technologies for Pallets Storing
}

\author{
Pavel Křŕž, Bronislav Chramcov and Milan Jemelka \\ Tomas Bata University in Zlin, Faculty of Applied Informatics, \\ nam. T.G. Masaryka 5555, 76001 Zlin, Czech Republic
}

\begin{abstract}
The paper highlights the problem oftechnology for pallet storing. The aim is to compare selected technologies and to find efficient warehouse solution for the real company, which produces a plastic parts for automotive and needs to solve storing in the new hall.The work describes differences between two pallet storing technologies - static racking system and powered mobile racking system. Comparison contains description, advantages and disadvantages of the both systems.Real data from real project are used for the evaluation of necessary parameters. The result presents proposal of solution which can meet all initial conditions.
\end{abstract}

Keywords: warehouse management, storing system,Static Rack system, Powered mobile rack system, Mobile bases for racking systems.

PACS: $89.20 . \mathrm{Bb}$

\section{INTRODUCTION}

Warehousing and inventory management are two important and closely knit activities that can have an impact on supply chain costs. There is enormous pressure to simultaneously increase throughput capacity and lower operating costs of warehouses. Throughput capacity models are comprised of picking policies, batching policies, storage assignment policies, as well as dynamic control models. Storage capacity models either find the optimal warehouse size or else maximize space utilization. Finally, questions such as rack orientation, space allocation and external building configuration are the focus of warehouse design models [1].A warehouse is a service facility, often comprising the only view that customers actually have of a manufacturing firm. The management of this facility has significant leverage over order leadtimes and fill-rate reliability. As with other service facilities, system design and operation are decision problems that are closely interlinked [2].

Nowadays, there are lots of stocking systems [3], i.e stocking on the floor, storing on the static high racking systems [4], on the powered mobile racking system [5], in fully automatic warehouse systems, vertical warehouse systems etc.To choose a correct storing technology it is necessary to know initial conditions and the final user requests. The initial conditions are given by free space for storing technology, type of loading unit, type of forklift for load unit manipulation, etc. The final user requests are given by the determination of production lot sizes and the assignment of storage space in a warehouse [6]. It is very important to choose not the cheapest one, not the biggest one, not with the highest turnover, but to choose the optimal solutionduring design of a new warehouse. Different methods are possible to use in this case [7], [8]. The most important is to know what the main request is, usually it could be the capacity, but if it is needed high speed of loading or unloading material, the most important is turnover. Parallel with these requests is of course the low cost solution. Always it should meet all the conditions.

This work finds efficient warehouse solution for the real company, which produces a plastic parts for automotive and needs to solve storing in the new hall.

\section{FORMULATION PROBLEM}

It is needed to solve storing requests for company's products, which are manipulated on EUR pallets. The new hall is already built and now it is needed to equip it by warehouse technology which can meet all the requests. The hall has a length of 40.3 meters and width of 29.6 meters. The height of hall is 12 meters. The entrepreneur defined essential specifications of warehouse system. It is requested minimal capacity (3.500 pallets),minimal turnover IN/OUT (60 pallets/hour) and technology price must be lower than BUDGET PRICE.There will be used handling carts for pallets manipulating in this warehouse. There will be used a reach truck, which can manage all pallets and a hand pallet truck which can manage only lower two rack levels. There can be used these technologies for this issue:

International Conference of Numerical Analysis and Applied Mathematics 2015 (ICNAAM 2015)

AIP Conf. Proc. 1738, 120027-1-120027-4; doi: 10.1063/1.4951910

Published by AIP Publishing. 978-0-7354-1392-4/\$30.00 
stocking on the floor, storing on the static racking systems, on the powered mobile racking system or in fully automatic warehouse systems. Stocking on the floor is very cheap, but the pallet with the material is not stackable and therefore the capacity is very low (approx. 400 - 740 pallets). Fully automatic warehouse systems are very efficient, but for a price much higher, than given in initial condition. Therefore there are compared static racking systems and powered mobile racking systems in this work. The goal of this work is to compare both technologies and find the best solution which can meet all initial conditions.

\section{COMPARED TECHNOLOGIES FOR PALLETS STORING}

The compared technologies for pallets storing are static rack systemand powered mobile rack system. The main parameters for the comparison are: capacity, price and turnover. The project data included the capacity and the price was provided by the supplier of the technology (O.S. Kreditspol. s r.o.), but in condition that the price will not be published. Therefore the price is expressed as ratio value of the BUDGET PRICE constant. Only the turnover must be calculated by means of project data and handling carts parameters. To be able to count the turnover (variable $T O$ ) is important to know the loading (unloading) pallet cycle time (variable $T$ ). This cycle time include a cart picking up a pallet at the place $A$, moving it to the place $B$, putting it and returning back to the place $A$.

Project data are racks dimensions (e.g. rack length, height and distances between in/out place and every aisle, mobile bases speed).Handling carts parameters are maximum speed and acceleration (deceleration). Precondition is that every handling cart is moving with constant acceleration and deceleration until the maximum speed or the distance is reached. The acceleration is equal to deceleration. If the cart needs to turn, it has to stop. The hall is equipped only by one in/out place - door. In an aisle can work only one handling cart at the same time. The aisle opening is provided by means remote control and opening starts at the beginning of the cycle.

\section{Static Rack System}

Static rack system is system which is still placed and anchored on the floor. There must be an aisle between every rack. The big advantage is the $100 \%$ availability of requested pallet. But unfortunately there is more than $50 \%$ of the hall capacity occupied by these aisles. The designed solution of static racks offers as much big capacity as is possible in the given area. Every different design of this technology has a smaller capacity. The capacity of this solution is 2334 pallets and the price is $27 \%$ of given BUDGET.Because both handling carts have an access to all aisles they can work at the same time in different aisles. The turnover is possible to express by the equation (1), where $T O_{R}$ is turnover of Reach truck and $T O_{H}$ is turnover of Hand pallet truck.

$$
T O_{\text {TOTAL }}=T O_{R}+T O_{H} .
$$

The turnover is possible in general to formulate in the form (2), where the average cycle time $T_{A v e}$ is sum of all cycle times divided by all pallet places, which a cart can reach. The average cycle time $T_{A v e}$ is defined according to the equation (3).

$$
\begin{gathered}
T O_{R_{-} o r_{-} H}=T_{A v e}^{-1} . \\
T_{\text {Ave }}=\frac{\sum_{i=1}^{n} T_{i}}{n} .
\end{gathered}
$$

A total cycle time can be expressed through the equation (4). It includes the sum of cart moving time between in/out place and aisle beginning $\left(T_{a}\right)$, cart moving time between aisle beginning and a rack column $\left(T_{c}\right)$, lifting of pallet to a cell height $\left(T_{h}\right)$ and manipulation time (loading/unloading) of pallet at location $\left(T_{m}\right)$. Because the cart has to return to start point some variables are multiplied by 2 .

$$
T_{i}=2\left(T_{a}+T_{c}+T_{h}\right)+T_{m}
$$

Every time is assumed by means of given distance, cart acceleration (deceleration) and maximum speed. The calculated average turnover for this solution is 71 pallets $/ \mathrm{hr}$. 


\section{Mobile Rack System - 1 Block}

Powered mobile rack is a fixed storage rack installed as a superstructure on mobile base. Mobile racks are assembled into a block moving on one rail track. Access in to the only manipulation aisle is reached by means of moving requisite bases at required block location. Mobile racks move on rail track installed in the floor. Any type of storage rack as a superstructure can be installed on mobile base. Mobile racks can be installed both in existing and new buildings. There is used one main aisle in front of mobile rack system block and one manipulation aisle in this solution (see FIGURE 1a).The big advantage is that the aisles occupied less than $20 \%$ of the hall capacity. The capacity of this solution is 4444 pallets and the price is $91.6 \%$ of given BUDGET.Because both handling carts have not an access to all aisles at the same time, only reach truck is used in warehouse. It can reach all locations. Thus, the total turnover is defined by equation (5), wherethe turnover of reach truck $\left(T O_{R}\right)$ is possible to express by equation (2).

$$
T O_{\text {TOTAL }}=T O_{R}
$$

A total cycle time is expressed through the equation (6) and it includes waiting time for opening the aisle $T_{o}$ in addition. The time $T_{o}$ takes the value in accordance with the form (7).

$$
\begin{gathered}
T_{i}=2\left(T_{a}+T_{c}+T_{h}\right)+T_{m}+T_{o} . \\
T_{o}= \begin{cases}T_{\text {open }}-T_{a} & \text { if } T_{\text {open }}>T_{a}, \\
0 & \text { otherwise. }\end{cases}
\end{gathered}
$$

The calculated average turnover for this solution is 48 pallets/hr.
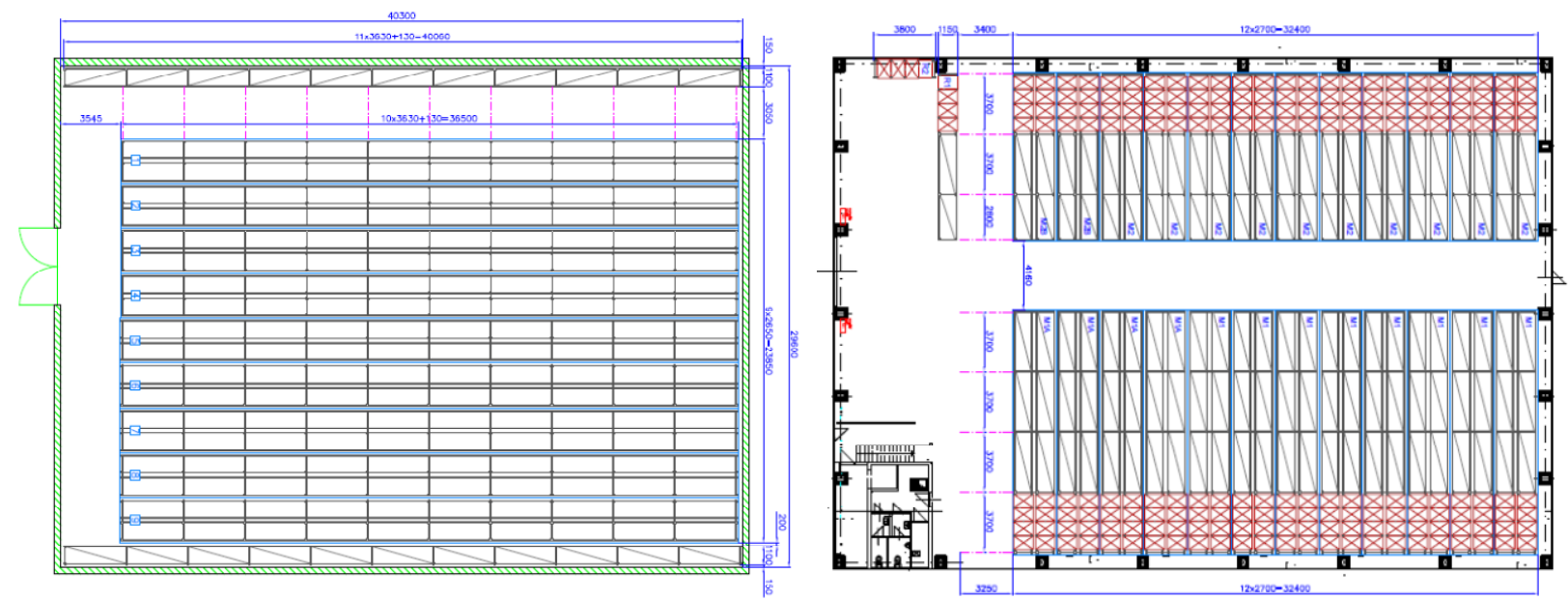

FIGURE 1. Designed Mobile Rack System in One Block on the left (a) and in two Blocks on the right (b) in the Hall (Warehouse).

\section{Mobile Rack System - 2 Blocks}

There are many possibilities how to design the mobile rack system. It can be divided in more blocks; it can be designed with more aisles, etc. This system is divided in two blocks and between them is the main aisle. Every block has one manipulation aisle for loading/unloading a pallet into/from the warehouse system (see FIGURE 1b). The big advantage is that the aisles occupied less than $31 \%$ of the hall capacity. The capacity of this solution is 3934 pallets and the price is $99.2 \%$ of given BUDGET.Because this solution has an opened aisle in every block, both handling carts can work at the same time in different aisles, and therefore the equations (1), (2) and (3) are possible to use for calculation of the turnover. Theequations (6) and (7) are used for expression of total cycle time. The calculated average turnover for this solution is 61 pallets $/ \mathrm{hr}$. 


\section{SUMMARY AND EVALUATION OF RESULTS}

Table 1 presents comparison of results for investigated technologies. The solution with the static rack system is very cheap and offers big turnover, but there is not met the requested capacity. We could increase the capacity with a new building but it would be more expensive than solution with powered mobile racks. Additionally, the company has no free area for other warehouse building. Next solution with Powered mobile rack system with 1 block can meet the requested capacity, but the turnover is too low.The best solution which can meet all company's requests is solution with powered mobile rack system with 2 blocks. The final capacity is $13 \%$ higher above than requested for future possible expansion. The total turnover is enough and if the company will need higher in the future, they can buy next cart(s).

TABLE 1. Comparison of results for investigated technologies.

\begin{tabular}{lccc}
\hline Technology & Capacity[pallets] & Turnover [pallets/hr] & Price [\% of BUDGET] \\
\hline Static Rack System & 2334 & 71 & 27,0 \\
Mobile Rack System - 1 Block & 4444 & 48 & 91,6 \\
Mobile Rack System - 2 Blocks & 3934 & 61 & 99,2 \\
Essential Specifications & Min 3500 & Min 60 & BUDGET PRICE \\
\hline
\end{tabular}

\section{CONCLUSIONS}

This paper compares the possible technologies for pallet storing in the automotive industry. The efficient solution is chosenwith accordance to the output data. Output data (price and capacity) was received from the supplier. The pallet turnover was calculated as an average value of all locations turnover. The selected solution meets all initial conditions and moreover is possible to have a free area space for design of offices (see FIGURE 1b).The benefits of this paper is possible using for similar projects where is needed to use efficient technology in defined space. The paper gives a manual forcalculationof total turnover for storing in powered racking system. This procedure can be used also for a simulation tool.Nowadays, there is almost not possible to increase the efficient in production line, because there was done almost everything in this field. But in supply chain is stillpossible to find efficient mainly in warehouses and this paper found solution which is effective and suitable.

\section{ACKNOWLEDGMENTS}

The work was performed with financial support of research project NPU I No. MSMT-7778/2014 by the Ministry of Education of the Czech Republic and also by the European Regional Development Fund under the Project CEBIA-Tech No. CZ.1.05/2.1.00/03.0089 andin part by Internal Grant Agency within the project No. IGA/FAI/2015/050.

\section{REFERENCES}

1. G. Cormier and E. A. Gunn, A review of warehouse models, European Journal of Operational Research, 58(1), 3-13 (1992).

2. A. E. Gray, U. S. Karmarkar and A. Seidmann, Design and operation of an order-consolidation warehouse: Models and application, European Journal of Operational Research, 58(1), 14-36 (1992).

3. R. Manzini (ed),Warehousing in the Global Supply Chain:Advanced Models, Tools and Applications for Storage Systems, Springer, 2012.

4. P. A. Król, M. Papadopoulos-Woźniak and J. Wójt, Experimental Investigation on Shear Strength of Hooking-type Beam-tocolumn Joints, Applied in One of High Storage Pallet Racking Systems, Procedia Engineering, 91, 232-237 (2014).

5. M. A. Tourdot, J. C. Muth, W. W. R. Lynt, W. B. McHenry, and S. M. Lehmann, Powered mobile storage system with select and drag operation and selectable aisle width feature,U.S. Patent No. US 20080133046 A1 (8 September 2006)

6. T. J. Hodgson and T. J. Lowe, Production Lot Sizing with Material-Handling Cost Consideration, AIIE Transactions, 14(1), 44-51 (1982).

7. E. Volna, M. Kotyrba and M. Janosek, „Knowledge discovery in dynamic data using neural networks.“ In Kuinam J. Kim, K. J. (ed.) Information Science and Applications. Lecture Notes in Electrical Engineering (Book series), Springer Verlag Berlin Heidelberg, 2015,Volume 339, pp. 575-582.

8. R. Jasek, A. Szmit and M. Szmit, Usage of Modern Exponential-Smoothing Models in Network Traffic Modelling. In Source of the Document Advances in Intelligent Systems and Computing, Springer Verlag, 2013, p. 435-444. 